progress in our effort to document sea level changes during earlier glacial cycles.

\section{References}

Andersen, M.B., Stirling, C.H., Potter, E.-K., Halliday, A.N., Blake, S.G., McCulloch, M.T., Ayling, B.F. and O'Leary, M. 2008: High-precision U-series measurements of more than 500,000 year old fossil corals, Earth and Planetary Science Letters, 265: 229-245.
Gallup, C.D., Edwards, R.L. and Johnson, R.G. 1994: The timing of high sea levels over the past 200,000 years, Science, 263: 796-800.

Potter, E.-K., Esat, T.M., Schellmann, G., Radtke, U., Lambeck, K. and McCulloch, M.T. 2004: Suborbital-period sea-level oscillations during marine isotope substages $5 \mathrm{a}$ and $5 \mathrm{c}$, Earth and Planetary Science Letters, 225(1-2): 191-204.

Scholz, D. and Mangini, A. 2007: How precise are U-series coral ages? Geochimica et Cosmochimica Acta, 71: 1935-1948.
Thompson, W.G., Spiegelman, M.W., Goldstein, S.L. and Speed, R.C. 2003: An open-system model for the U-series age determinations of fossil corals, Earth and Planetary Science Letters, 210 365-381.

For full references please consult:

www.pages-igbp.org/products/newsletters/ref2009_2.html

\title{
Using models to inform the field community: Far-field sea level data applications
}

Glenn A. Milne

Department of Earth Sciences, University of Ottawa, Canada; gamilne@uottawa.ca

\section{Far-field sea level data contain information on past global ice volume and the source distribution of meltwater pulses. To extract this information in an accurate and effective manner requires site selection that is informed by model output.}

When ice sheets and glaciers exchange mass with the oceans, the resulting sea level response is spatially variable due to the influence of the mass redistribution on the solid Earth and the gravity field (Farrell and Clark, 1976). The spatial and temporal variability in the sea level response reflect the evolution of grounded ice, as well as the physical structure and properties of the Earth's interior. Observations of this response can therefore be inverted to infer information on past ice sheet evolution and solid Earth structure. This inversion procedure generally requires the use of a model that relates the relevant model parameters (ice evolution and solid Earth properties) to the observable quantity (sea level). In this short paper, the process of using far-field sea level observations (i.e., those distant from major glaciation centers) to constrain the past evolution of ice sheets is reviewed. Emphasis is placed on two recent papers that use model predictions to determine optimal locations to solve a particular problem (Clark et al., 2002; Milne and Mitrovica, 2008). In doing so, these studies promote a two-way dialog between the observational and modeling communities that is necessary for efficient progress in solving outstanding problems.

\section{Inferring past global ice volume}

A classic application of far-field sea level data is the inference of past global ice volume through estimates of eustatic sea level (e.g., Fleming et al., 1998). This is the component of sea level change associated with a raising or lowering of ocean surface height through mass exchange with the cryosphere, and is calculated by simply dividing the volume of grounded ice gain/ loss by the area of the ocean (and multiplying by the density ratio of ice to water to account for the volume change in the phase transition). This procedure has been ap- plied to infer past global ice volume at different times. For example, measurements of the sea level lowstand during the Last Glacial Maximum (LGM) have been used to infer the magnitude of grounded ice volume at that time (e.g., Yokoyama et al., 2000). Another important application is the use of sea level observations in the mid- to late-Holocene to infer ice volume changes prior to the industrial era (e.g., Nakada and Lambeck, 1989), as a reference of natural variability in the system.

Accurate application of this procedure is complicated by the fact that, even in farfield locations, the actual (observable) sea level change deviates significantly from the eustatic component of the change due to isostatic and tectonic processes (e.g., Clark et al., 1978). For this reason, even observations from tectonically stable areas must be corrected for isostatic effects before being used to infer a paleo ice volume (e.g., Milne et al., 2002). This correction procedure is based on a model and so is subject to some degree of error that depends on the accuracy of the model prediction at a given locality. The error can be minimized by choosing locations where: (1) sea level is close to the eustatic value, so as to limit the magnitude of the correction, and/or (2) the correction to be applied is relatively insensitive to uncertainties in ice/Earth model parameters. Milne and Mitrovica (2008) carried out a model sensitivity study to map

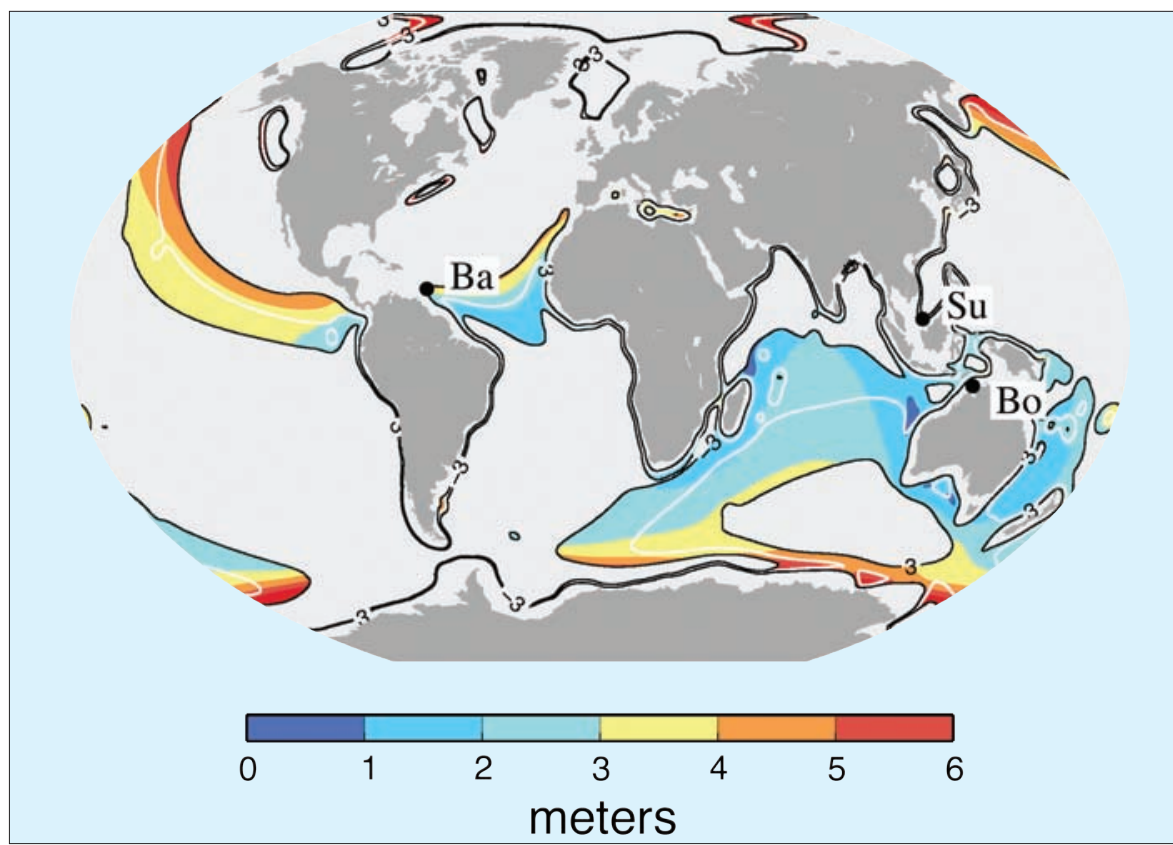

Figure 1: Output for a large suite of model runs based on a single ice model and 162 Earth viscosity models. Results are shown for the Last Glacial Maximum (LGM; 21 cal ka BP). White contours indicate where the (mean) predicted sea level is equal to (mean) eustatic sea level. Black contours indicate where these values deviate by $\pm 3 \mathrm{~m}$ (deviations $>3 \mathrm{~m}$ are masked by the light-gray shading). Colored contours show standard deviation of the predictions due to changes in Earth viscosity structure. Values of low standard deviation (blue colors) indicate where model predictions are insensitive to variations in Earth viscosity structure. Optimal localities for measuring sea level to estimate past ice volume are where the predicted sea level is close to the eustatic value (i.e., near the white contour) and the standard deviation is low (i.e., blue colors). Three locations where LGM sea levels have been measured are shown: Barbados (Ba), Bonaparte Gulf (Bo) and Sunda Shelf (Su). See Milne and Mitrovica (2008) for more details. 
out where these criteria are best satisfied. Figure 1 shows these results for the LGM. Similar maps were developed for a number of times from the LGM to the late Holocene. In principle, maps like that shown in Figure 1 can be generated for older times (e.g., last interglacial). However, the relatively poor constraints on global ice-evolution prior to the LGM will likely be a limiting factor in generating accurate maps for this earlier period.

\section{Inferring distribution of rapid ice mass loss during meltwater pulses}

Departures from eustasy complicate the extraction of an ice-volume signal from far-field sea level data. On the other hand, these departures contain the information required to infer the geometry of melt sources during periods of rapid sea level rise. This method, known as "sea level fingerprinting", is particularly powerful in farfield areas, as the spatial variability is dominated by gravitational changes that can be computed with a high degree of accuracy.

Successful application of the fingerprinting technique depends on the precision and distribution of data that capture a given melt event. Clark et al. (2002) applied the fingerprinting technique using data at Barbados (Fairbanks, 1989; Bard et al., 1990) and Sunda Shelf (Southeast Asia; Hanebuth et al., 2000) to consider which ice sheets were responsible for the $\sim 20 \mathrm{~m}$ rise in sea level between 14.5 and 14 cal ka BP (known as meltwater pulse IA - mwp-IA). Because of the limited number of data sets at their disposal, a unique solution was not found. However, the authors were able to rule out a southern Laurentide source since the predicted rise at Sunda is $40 \%$ larger compared to Barbados and the observed rise is of similar magnitude at each location. They went on to demonstrate that these two data sites are compatible with a number of source distribution scenarios and presented a figure (reproduced here as Fig. 2) to illustrate which melt scenarios are compatible with the available data constraints (from Barbados and Sunda). This figure also shows how data from other locations could add information to help solve the problem. For example, data from the Argentine shelf would prove highly effective in testing a scenario that included a dominant Antarctic source because the predicted rise at this site is significantly lower compared to the other sites considered for each of the three Antarctic source scenarios.

Determining the ice sheet(s) responsible for mwp-IA remains an outstanding problem that will require improved data control in both far- and near-field locations before a robust solution can be found.

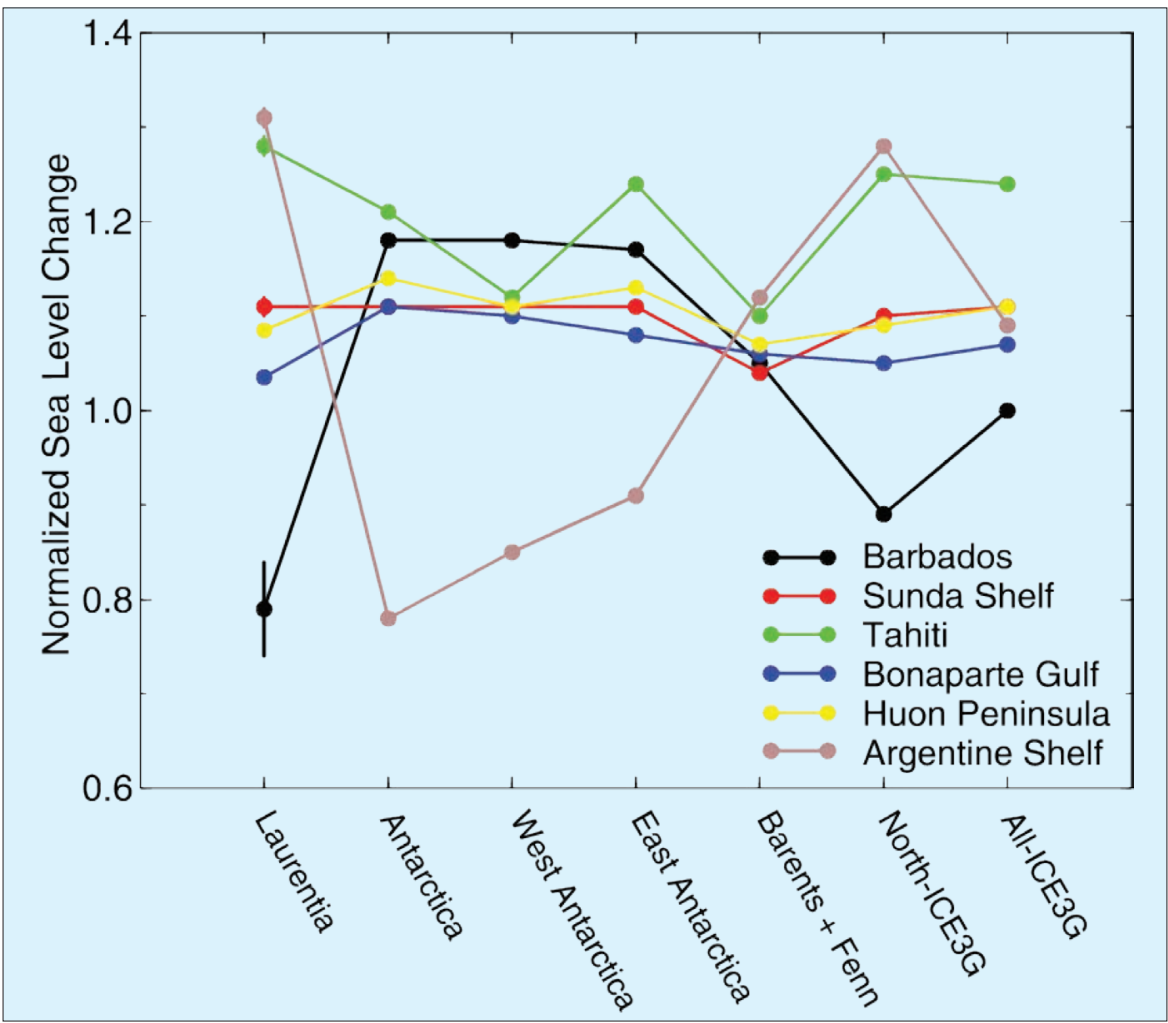

Figure 2: Sea level predicted at 6 sites (color-coded) for 7 distinct melt source scenarios ( $x$-axis). Each line shows the sea level rise predicted at a given location for the 7 source scenarios considered. This information can be used to choose sites that would be effective in better constraining the melt-source distribution of meltwater pulse IA. Good sites for discriminating between different scenarios are those that exhibit a large difference in predicted rise compared to other sites. For example, precise data from the Argentine Shelf would provide a powerful test of an Antarctic source scenario. Note, the predicted rise has been divided by the model eustatic value so that the results can be applied to fingerprint any rapid melt event regardless of magnitude. For example, an event of ice volume loss equivalent to $10 \mathrm{~m}$ eustatic rise would result in a sea level rise of $\sim 8 \mathrm{~m}$ (i.e., $~ 80 \%$ of the eustatic value) at the Argentine Shelffor an Antarctic source. See Clark et al. (2002) for more details.

Meltwater pulses demonstrate that ice sheets can lose a large amount of mass over only a few centuries (rates of change on the order of meters per century). What is the possibility of such events occurring in the future? An event like mwp-IA, with magnitude $\sim 20 \mathrm{~m}$, can be ruled out given that this event occurred during a time of near peak glaciation when a large volume of ice was grounded on shallow continental shelf (and therefore highly sensitive to climate change). However, it is less clear if rates of change similar to those produced during these extreme past events can be reproduced in the future given the current configuration of ice sheets. One way to address this question is to first better understand the forcing and responses that produced meltwater pulses. Once the source distribution is constrained, appropriate regional data and models can be applied to consider the most likely forcing and response mechanisms. Reproducing events like mwp-IA will certainly be a challenge for the current generation of glaciological models particularly if it was sourced primarily, from a single ice sheet.

\section{Summary}

Proxy sea level observations contain important information on how the cryosphere has responded to past climate change. In- terpretation of the paleo sea level record for this purpose is non-trivial due to the spatial complexity in the sea level response to land ice change. As a consequence, the use of a sea level model is required to obtain a robust inversion of sea level data, even at locations distant from the major glaciation centers. As illustrated above, the locations of data sites are crucial to arrive at well-constrained solutions to a given problem. The use of sea level models to identify optimal sites is a powerful way to focus future field initiatives so that robust solutions can be found in an efficient manner.

\section{References}

Clark, J.A., Farrell, W.E. and Peltier, W.R., 1978: Global changes in postglacial sea level: a numerical calculation, Quaternary Research, 9: 265-287.

Clark, P.U., Mitrovica, J.X., Milne, G.A. and Tamisiea, M., 2002: Sea-level fingerprinting as a direct test for the source of global meltwater pulse 1A, Science, 295: 2438-2441.

Farrell, W.E. and Clark, J.A., 1976: On postglacial sea-level, Geophysical Journal of the Royal Astronomical Society, 46: 647-667.

Fleming, K., Johnston, P., Zwartz, D., Yokoyama, Y., Lambeck, K. and Chappell, J., 1998: Refining the eustatic sea-level curve since the Last Glacial Maximum using far- and intermediate-field sites, Earth and Planetary Science Letters, 163(1-4): 327-342.

Milne, G.A. and Mitrovica, J.X., 2008: Searching for eustasy in deglacial sea-level histories, Quaternary Science Reviews, 27: 2292-2302.

For full references please consult:

www.pages-igbp.org/products/newsletters/ref2009_2.html 